\title{
Challenges, implications and the future of the Australian Curriculum: The Arts
}

\author{
Martin Kerby ${ }^{1}$ (D) - Linda Lorenza ${ }^{2}$ D Julie Dyson ${ }^{3} \cdot$ Robyn Ewing $^{4}$ (D) \\ Margaret Baguley ${ }^{1}$ D
}

Received: 17 August 2021 / Accepted: 22 September 2021 / Published online: 12 October 2021

(c) The Australian Association for Research in Education, Inc. 2021

\begin{abstract}
This paper will explore the key findings identified in the five arts discipline-specific papers which comprise this special theme issue. Each of the participant researchers have situated Dance, Drama, Media Arts, Music and Visual Arts within the context of the Australian Curriculum: The Arts and what they characterise as its social justice imperatives. A narrative phenomenological approach has been adopted to enable the participant researchers to socially co-construct an analysis of their experiences working with the Australian Curriculum: The Arts including challenges, implications and the future for their respective discipline areas and the Arts overall. The three key themes from these collective voices revealed a quality arts education is an entitlement for every child and young person; the Arts provide important opportunities for children and young people from diverse backgrounds and cultures to demonstrate their learning, express themselves and participate; and arts educators and the Arts industry need to work together to strengthen community understanding about the value of the Arts in education. This process provided important insights into how exposure and engagement with the Arts shape the ways in which children and young people make meaning in their lives, enhance their overall wellbeing, increase their sense of social responsibility and contribute to a socially-just society.
\end{abstract}

Keywords Arts education · Arts educators · Arts industry practitioners · Arts integration · Australian Curriculum: the Arts · COVID-19 · Phenomenology · Social justice $\cdot$ National curriculum

Margaret Baguley

baguley@usq.edu.au

1 School of Education, University of Southern Queensland, Springfield, Australia

2 School of Education and the Arts, Central Queensland University, Rockhampton, Australia

3 National Advocates for Arts Education (NAAE), Milton, Australia

4 School of Education and Social Work, The University of Sydney, Sydney, Australia 


\section{Introduction}

It was the best of times, it was the worst of times, it was the age of wisdom, it was the age of foolishness, it was the epoch of belief, it was the epoch of incredulity, it was the season of light, it was the season of darkness, it was the spring of hope, it was the winter of despair.

A Tale of Two Cities, Charles Dickens (1859)

Dickens' book A Tale of Two Cities (1859) explores the economic and political unrest in London and Paris, exemplified through social and class injustices, which led to the American (1765-1783) and French Revolutions (1789-1799). During the current COVID-19 pandemic, the major themes of duality, revolution and resurrection that Dicken's explores are all too familiar as local, national and international governments struggle to respond to the most serious economic crisis since the Second World War (OECD, 2020). Haase (2020, p. 1) contends that the COVID-19 pandemic has highlighted and reinforced the "existing social, socioeconomic and socio-spatial inequities in our cities". As the famous lines from Dickens illustrate, during periods of social and political upheaval, people draw on a range of opposites, contrasts and provocations to explore and articulate their understanding of their world, both at a local and international context. The Arts are a particularly rich storehouse of symbols, metaphors and allusions for people seeking to understand and express complex ideas as "the blurring the lines between disparate entities invites multiple interpretations even as it achieves clarity of thought" (Davis, 2008, n.p.; Kerby et al., 2016).

During the COVID-19 pandemic, people across the globe have been tuning into the Arts online to cope with the challenges of isolation due to the COVID-19 pandemic (Choi, et al., 2020; Lorenza, 2020; Mak, et al., 2021; Tam, 2020; UNESCO 2021a). The pandemic has therefore further highlighted the importance of the Arts in providing students with "safe, playful, imaginative space[s] to share, explore and make sense of the experiences and issues that they feel uncomfortable about" (Tam, 2020, p. 632). However, official recognition by the Australian government that the Arts are an integral part of a holistic education predated the pandemic by some years. On 30 July, 2013, the Education Ministers formally endorsed the Arts curriculum "subject to further consultation with Western Australia" (Lorenza, 2018, p. 66). Western Australia had requested a year by year curriculum, not the two-year bands previously agreed to by the Shape paper in 2011. The Arts curriculum was resolved and made available to states and territories for their use via the Australian Curriculum website on 18 February, 2014 with the disclaimer "available for use awaiting final endorsement" (Lorenza, 2018, p. 68). This process was again stalled when the then Minister for Education, Christopher Pyne, called for a full review of the whole Australian Curriculum. As Lorenza (2018, p. 69) contends "since 2015, all States and Territories have adopted the Australian arts curriculum except for New South Wales". The inclusion of the Arts' in the Australian Curriculum aims to develop "successful learners, confident and creative individuals, and active and informed citizens" (MCEETYA, 
2008 , p. 8). The Arts curriculum also provides students with the opportunity to access and engage through the artistic processes of creating, performing, presenting, producing, responding and connecting which "creates a sense of normalcy, possibility, community, and hope during this challenging and uncertain time in history" (Joseph, 2020, p. 73).

A significant issue that arose in consultation discussions was the policy inclusion of Dance, Drama, Media Arts, Music and Visual Arts as equivalent art forms within one curriculum (ACARA, 2011). This expanding of mandatory arts disciplines was a re-conceptualisation that challenged the traditionally privileged status of Music and Visual Arts (Comte, 1988; Pascoe et al., 2005). Though it has remained a point of contention, at the time the proposal was supported by numerous stakeholders, most notably the National Advocates for Arts Education (NAAE) (Cosaitis, 2011; Ewing, 2010, 2020). NAAE was supported in its advocacy by both arts professional associations and industry bodies, as well as actors, artists and other creatives. Nevertheless, the Arts curriculum has posed a challenge to the preparedness and expertise of teachers, first by moving to a position that all five art forms have equal status in the curriculum, and second, in the expectation that primary teachers would teach all five art forms (Cosaitis, 2011; O'Toole, 2019).

The three-dimensional model of the Australian Curriculum (ACARA, 2021) comprises a matrix approach to curriculum and includes, alongside the disciplinary knowledge in eight learning areas (English; Mathematics; Science; Humanities and Social Sciences; the Arts; Technologies; Health and Physical Education; Languages), three cross-curriculum priorities (Aboriginal and Torres Strait Islander Histories and Cultures; Asia and Australia's Engagement with Asia; and Sustainability) and seven general capabilities (literacy; numeracy; information and communication technology; critical and creative thinking; personal and social capability; ethical understanding; and intercultural understanding). This triadic curriculum model is informed by local political and social contexts, as well as globalisation agendas which promote "national competitiveness and economic development" (Gleeson, et al., 2020, p. 478). It also formalises the place of general capabilities, which had previously been part of the 'hidden' curriculum of skills or competencies that were neither measured nor reported upon (Eisner \& Vallance, 1974; Gilbert, 2019). The expressiveness and transformational nature of the Arts, in addition to their links to social justice by providing exposure to diverse cultural themes and issues, are a natural fit with the Australian Curriculum's general capabilities and cross-cultural priorities, particularly in supporting the two goals of the Alice Springs (Mparntwe) Education Declaration, agreed to by all of Australia's State and Territory Education Ministers (Australian Government, 2019, pp. 4-5):

- Goal 1: The Australian education system promotes excellence and equity; and

- Goal 2: All young Australians become confident and creative individuals, successful lifelong learners, and active and informed members of the community.

The Arts enable students to engage in a range of sensory experiences and the opportunity to experiment, to imagine, to play, and explore as they discover how to communicate, share and create with others. The Arts promote understanding of 
diversity by engaging students with different cultural experiences which are often integrated through the storytelling worlds of Drama and Media Arts, the physical imagination of Dance, the visual escape from the body and self-enablement through Visual Arts, or the aural sanctuary that is created when making or listening to Music (Barrett, 2019; Barton \& Baguley, 2017; Bresler, 2007; Burridge \& Dyson, 2020; Dezuanni, 2017; Eisner, 2009; Ewing, 2010; Ewing, 2019a; Ewing, 2019b; Fleming et al., 2015a; Fleming et al., 2015b; Grierson, 2011; Meiners, 2014; O’Toole, 2009).

\section{Contextual background}

The following section provides a contextual background to this paper, including the valuing of the Arts and Arts education during the COVID-19 pandemic, the importance of the Arts and particularly Arts education during times of crisis, and the importance of Arts educators and Arts industry practitioners speaking with one voice.

\section{Valuing of the Arts and Arts education during the COVID-19 pandemic}

Arts educators are routinely challenged to quantify the contribution their respective disciplines make to furthering Australia's prosperity in the national and global context (Australian Government 2019). Although the Arts are one of the eight learning areas in the Australian Curriculum, arts organisations and arts courses in higher education have nevertheless suffered severe reductions to funding during the COVID-19 pandemic. The Organisation for Economic Co-operation and Development (OECD, 2020) has identified the Arts as one of the areas most at risk due to the impact of social-distancing restrictions resulting from the COVID-19 pandemic. Yet, when the Arts are disenfranchised and cease to be valued as a vital component in an authentic and holistic education, by default, "the value of people's lives, individual identities and rights" are open to sustained challenge (Morgan, 2018, p. 96). For as Sabol (2021, p. 2) argues, "fundamental beliefs about the value of an education in art are critical for developing productive citizens in a democracy". In the Australian context, the Arts are well able to respond to the demands of the national curriculum, for in addition to helping students learn about and through the Arts, they can make a unique contribution to the "development of children into compassionate and democratic citizens who can create a more liveable word, and become creative and innovative contributors" (Morgan, 2018, p. 96).

The impact of the COVID-19 pandemic has reverberated across education. Face to face arts teaching has been replaced by online learning and numerous arts organisations are now entirely reliant on government support (Hands, 2020; Sabol, 2021; Turner, 2020; Tuttle \& Hansen, 2021). The Australian Government recognises that the effects of COVID-19 on the creative and cultural sector "have been severe" (Commonwealth of Australia, 2021, p. 24). In the May 2021 Australian government budget, approximately $\$ 300$ million was allocated to "help activate and support the successful reopening of Australia's creative and 
cultural sector" building on almost $\$ 800$ million in targeted support (Commonwealth of Australia, 2021, p. 24). However, the general assessment by Arts industry practitioners is that the federal government has provided a 'small and late' response to their call for an $\$ 850$ million rescue package in March, 2020 (Dye, 2020; Turner, 2020). The landmark study Creating our Future (Australia Council for the Arts, 2020) that examines the engagement of Australians with the Arts showed "a growing number of Australians value the Arts for its role in building social cohesion, personal happiness, overcoming stress and anxiety and driving economic growth" (Morris, 2020, para. 2). In spite of these important findings, however, unprecedented events such as COVID have "been the great clarifier, revealing the priorities of societies and governments" (Turner, 2020, para. 17). Governments need to address the immediate health concerns of the pandemic, yet are not always cognisant of the critical role of the Arts towards in keeping people connected and inspired around the world, thereby contributing to positive mental health (O'Connor \& Estellés, 2021; Sabol, 2021; Tam, 2020).

In late 2020, the Australian government amended the HESA (Higher Education Support Amendment) Act, which altered the funding rates for some disciplines to drive greater undergraduate enrolment growth in areas of national priority and in areas where it is anticipated there will be greater future jobs growth and opportunities (Marshman \& Larkins, 2020). Teaching, nursing, agriculture, STEM (science, technology, engineering and maths) and Information Technology were the most notable beneficiaries. The subsequent Job-ready Graduates Package seeks to "deliver more job-ready graduates in the disciplines and regions where they are needed most and help drive the nation's economic recovery from the COVID-19 pandemic" (Australian Government, 2021, para. 3). The National Advocates for Arts Education (NAAE) (2020, para. 11) understood that behind the bureaucratic language, there is an existential threat to arts education which will impact on university offerings in Arts teaching courses. Though it will come as no comfort to Arts educators, these challenges are not unique to the Australian context. Developments in the United Kingdom and the USA indicate that the Arts are not a strategic government priority even during times when collaborative, critical and creative thinking are required to tackle global problems such as the COVID-19 pandemic (Baguley, et al., 2020). The United Kingdom recently approved a fifty percent funding cut for art and design courses and redirected the savings to science and medicine (Harris, 2021; Rea, 2021). In their assessment of the impact of the COVID-19 pandemic in the USA, Guibert and Hyde (2021, p. 3) acknowledge that the sporadic employment of artists has led to even "greater vulnerability and financial burden". However, they also commended arts organisations, artists and performers for "finding innovative ways to adapt and survive during the pandemic", with online tools providing an opportunity for these groups to "reach many more audiences during the pandemic than might have been possible otherwise" (Guibert \& Hyde, 2021, pp. 6-7; UNESCO (2021)). The 'digital turn' for arts educators and arts industry practitioners, however, is not a panacea, for individuals, groups or organisations are not always able to afford the technology and re-skilling required to "monetize their offerings in a virtual environment" (Guibert \& Hyde, 2021, p. 7). 


\section{Importance of the Arts and Arts education during times of crisis}

In a joint address during the 2021 International Arts Education Week (24 - 30 May), Ms Stefania Giannini, Assistant Director-General for Education of UNESCO and Mr Ernesto Ottone R, Assistant Director-General for Culture of UNESCO acknowledged that culture and the Arts, such as music on balconies and the sharing of digital content, have been an important source of solace and connection during lockdowns throughout the COVID-19 pandemic. UNESCO also emphasised that arts education not only involves learning about the Arts but learning through the Arts, motivating students to learn, deepening the learning experience and "promot[ing] values grounded in peace, inclusivity, and respect for cultural diversity" (UNESCO, 2021). In launching the ResiliArt global movement for arts and cultural professionals, Audrey Azoulay, the Director-General of UNESCO, affirmed that arts education not only helps people deal with crisis situations but also contributes to "socio-emotional well-being and improves learning outcomes" (UNESCO, 2020). In May 2020, the United States National Arts Education Association (National Art Education Association (NAEA), 2021) released a joint statement on behalf of numerous organisations emphasising the importance of providing an arts education for all students. The document titled 'Arts Education is Essential' outlines the following three principles:

- Arts education supports the social and emotional wellbeing of students, whether through distance learning or in person;

- Arts education nurtures the creation of a welcoming school environment where students can express themselves in a safe and positive way; and

- Arts education is part of a well-rounded education for all students as understood and supported by federal and state policymakers. (para. 3)

Professor Peter O'Connor, an internationally recognised expert in theatre and drama education, has implemented these principles across a range of contexts to support children when they return to school after experiencing traumatic events (Gibbs, et al., 2013). At the beginning of the pandemic, he worked with a team of arts educators from across New Zealand and Australia to develop the resource Te Rito Toi which has been used in 114 countries (University of Auckland, n.d.). Te Rito Toi uses arts-informed curricular approaches to provide "powerful methods for individual and community recovery during and after disaster" and participatory artsbased methods to "strengthen social support and help people to build critical hope" (O’Connor \& Estellés, 2021, p. 1). O’Connor's research on Christchurch schools during the earthquakes in 2011 and 2012 found that teachers continued to focus on preparing students for the future rather than "helping children make sense of their present" (O'Connor \& Estellés, 2021, p. 3). The intention of Te Rito Toi was therefore to assist teachers in creating a shift in their pedagogy and to provide a curriculum resource that responded to the changed circumstances of COVID-19. Te Rito Toi draws from the work of Paulo Freire (1998) and Noddings (2005) to create and inform a pedagogy of love and care. O'Connor and Estellés (2021, p. 1) described how the team of arts educators who created Te Rito Toi knew that "the arts uniquely protect participants into, not from, emotion" [emphasis added]. Drawing on the work 
of Gavin Bolton (1986), O'Connor and Estellés (2021, p. 1) argue that "the purpose of providing spaces through the arts for dialogue is not so that emotional response is removed from the situation, rather the space allows an opportunity for people to feel in a safe manner" [emphasis added].

The importance of schools as sites of caring communities has been brought into even sharper focus during the pandemic. As Sabol (2021, p. 4) observes, arts educators have worked tirelessly during the pandemic and have "stepped up and acted". Their efforts have been "highly creative and included nearly infinite variety and unbounded innovation". Joseph (2020, p. 73) was likewise moved to write that arts educators are "determined to be successful and demonstrate resilience in the face of adversity and ambiguity". However, globally there have been issues with equity and access; connectivity to the internet, expertise with technology, and access to arts supplies that favour wealthier families, with low socio-economic status being, as always, a "huge risk factor" (Haase, 2020, p. 1; Joseph, 2020). However, Sikkema et al., (2021, p. 21) argue that the pandemic has also provided an opportunity to bring the Arts from the margins of the curriculum to the centre of learning and to "work with students and communities to rethink what school can and should look like". Berry (2020, p. 16) contends that the pandemic has encouraged educators to "reach out to students, check in on them and their families, and support them as whole children, not as test-takers" (O’Connor \& Estellés, 2021; Sikkema et al., 2021). During the pandemic, students and teachers have had the opportunity to meet 'virtually' in each other's homes, thereby challenging the hierarchy that has traditionally defined teachers' interactions with students (Conaty, 2020; Sikkema et al., 2021).

Eisner $(2002,2009)$ contends that the Arts offer a valuable lesson for those seeking to create the kind of schools that children deserve and society needs. He argued that the Arts use higher order thinking skills, employ problem-solving strategies, explore a range of unique processes and tools to communicate complex ideas, and encourage consideration of alternative ways of knowing and communicating. In doing so, he acknowledged that when a society includes the Arts in its curriculum it makes a profound statement to students about what society believes is important (Sabol, 2021). This value extends far beyond a philosophical statement of belief. For example, in a recent empirical study on Australian preschool children during the COVID-19 pandemic, Vasileva et al., (2021, p. 6) found that they used 'magical thinking' to help understand the crisis. The children engaged in imaginary play (drama) to cope with stress and to process what was happening, making them feel as though they had some control over what appeared to be a chaotic world. Arts educators have long been aware of the transformative potential of the Arts and possibilities inherent in an arts-led curriculum (Ewing, 2010; Goldberg, 2021; Rago \& Gibson, 2021).

For all the controversy surrounding its genesis, the triadic model of the Australian Curriculum recognises that "disciplines are not self-contained or fixed but are interconnected" (Moss, et al., 2019, p. 24). In spite of this recognition, curriculum delivery has been re-prioritised due to the emphasis on high-stakes testing in areas such as literacy and numeracy. The current crisis is not just a deficient, for it has provided an unprecedented opportunity to 'reset' traditional ways of thinking about education 
with a "powerful counterargument against universal curriculum top-down professional development, [and] the compartmentalization and containment of parent and neighborhood voice" (Sikkema, et al., 2021, p. 25). The speed at which traditional institutions such as schools have had to 'pivot' shows that it is possible to reconsider "standardized curricula, compliance-oriented formulas, regulations, [and] centralized management and move towards a more equitable education that emphasises inquiry and exploration, student voice, and relationship building" (Sikkema, et al., 2021 , p. 25). These approaches are, pedagogically speaking, the bread and butter of arts education. The cancellation of the 2020 National Assessment Program for Literacy and Numeracy (NAPLAN) in Australia for students in Years 3, 5, 7 and 9 due to COVID-19 has driven an interrogation of a test that "reduces intelligence into a kind of mechanistic and narrow area of knowledge ... it doesn't really say [anything] about the other intelligences that children might have" (Pasi Sahlberg, cited in Duffy $\&$ Sadler, 2020, para. 30). The Arts are comfortable with the type of ambiguity that COVID-19 has brought to the educational landscape, and might well thrive in them (Sabol, 2021). The qualities that the Arts teaches are critical to helping students to understand, express themselves and to cope with these times of uncertainty and challenge during the pandemic.

\section{Arts educators and Arts industry practitioners speaking with one voice}

Australian schools are under increasing pressure to raise academic standards with an ever increasing focus on areas such as literacy and numeracy, which are often quarantined from areas such as the Arts and the Humanities despite their potential to provide broader-based cross-curricular approaches and themes (Eaude \& Catling, 2019; Nussbaum, 2017; Sears \& Clark, 2020). Ken Robinson (cited in Burnaford et al., 2011, p. xx) acknowledged that the role of teachers has become increasingly complex, compounded by a range of social, economic and technological changes and that too often the Arts are "pushed to the edges of education at the very moment when what they offer is urgently needed at the centre of it". Centralising the Arts in the curriculum would change the conversation from "how special the arts are, [to] how normal we are" (Evans, cited in Turner, 2020, para. 48). For as Rachel Healy argues, the Arts are currently viewed as more of a series of islands rather than a unified sector (cited in Turner, 2020, para. 47). This compartmentalisation does not always emanate from outside of the Arts, and in fact came to dominate the drafting of the foundation document for the national Arts curriculum. Many arts advocates were so determined to protect the integrity and boundaries of their arts forms that they "engage[d] in both collaborative endeavour and power struggles to draft, consult and resolve complex contestations" (Meiners, 2014, p. 225; O'Toole, 2013). Dr Jeff Meiners, the Dance foundation arts shape paper writer, recalls that during the process "collegiality, resilience and trust were needed as individuals ... the larger group handled assaults on their integrity and intellect in public media commentaries and critiques, which included a discourse of denigration and dissidence" (2014, p. 230). Eltham (2014, para. 9) recognised the extensive work undertaken in developing The Australian Curriculum: The Arts and "though eternally controversial, the 
arts curriculum delivered". With five separate arts subjects and a "new and innovative subject titled "media arts" which recognised the impact of digital and screenbased devices in the lives of twenty-first century citizens, it broke new ground in the Australian education system, though it was a success born of compromise.

The Australian Curriculum: The Arts (ACARA, 2015) states that although the Arts is a learning area that "draws together related but distinct art forms", they are also often used in interrelated ways, with each involving "different approaches to arts practices and critical and creative thinking that reflect distinct bodies of knowledge, understanding and skills". Rich and deep arts learning occurs when students can see the relationship between what they are learning and their own lived experience and the wider world. Each of the Art forms have unique histories, language and approaches. Any discussion of the possibility of integrating the Arts with themselves or more particularly with other subject areas has traditionally been problematic because of fears that it will take time away from high-stakes testing, (Lingard et al., 2016; Moss et al., 2019), the lack of teacher self-efficacy with arts integration (Battersby \& Cave, 2014; Burnaford et al., 2011) and limited teacher professional development (Hipp \& Sulentic Dowell, 2019; O'Toole, 2018). Davis (2008) and O'Toole (2018) both argue that arts educators are also concerned that the integration of the Arts with other subjects will obscure the view of the Arts as unique disciplines:

Every teacher of an art form has had their subject traduced into menial service as a handmaiden for another subject or even art form - music reduced to rhythm games for maths, visual arts co-opted into painting the sets for the school musical, drama diminished into little skits for history or school camp, media arts turned into critical literacy exercises in English, dance merely a back alley in physical education, and in primary schools all of them lumped together into an amorphous and ill-defined form of Friday afternoon relief called Expressive Arts. (O’Toole, 2018, p. 430)

However, as Ewing (2020, p. 78) reveals, there was an "experiential and crosscurricular approach to arts programming" foreshadowed in The Australian Curriculum: The Arts, which is more meaningful than dividing the time between the different arts disciplines. She further argued that "deep learning and understanding is more likely when integration is carefully planned to reflect real-world learning experiences" (Ewing, 2020, p. 78). There is a plethora of evidence that arts integration supports active learning and engagement and deeper, more sustained learning (Burnaford et al., 2011; Goldberg, 2021; Hipp \& Sulentic Dowell, 2019). However, as Marshall (2014, p. 105) argues, arts educators need to "fully delineate and promote art integration as the complex, dynamic practice it is so that those outside the field can see its potential". She identifies a number of important considerations regarding transdisciplinary approaches using the visual arts as an example. The web metaphor offered by Klein (2000, cited in Marshall, 2014, p. 107) outlines how arts integration works through collaboration between arts educators and arts industry practitioners using a transdisciplinary approach: "Its web is constructed by three kinds of practitioners: (1) artists and specialists in other disciplines or fields who spin the disciplinary threads (spinners); (2) art educators (weavers) who weave these threads 
together; and (3) learners (weavers) who further weave threads into their own fabric of understanding".

Arts integration is far from being an under-theorised phenomenon. Gardner's (1983) theory of multiple intelligences informs the Arts Integration movement and highlights the importance of engaging students' difference intelligences by diversifying methods of teaching (Snyder, et al., 2014). Erikson (2000, cited in Snyder et al., 2014, p. 4) found that arts integration allows for "a natural, meaningful connection among one or more art forms and one or more subject areas to help students master significant content and/or skills in both". Griss (1994, p. 79) argues that the Arts and education are inseparable, as "you cannot study the arts without learning concepts of math, science, history and problem solving, nor can you be truly educated if you are ignorant of the role of arts in culture and history". Snook and Buck (2014, p. 24) posit that "all subject areas [should] be seen less as silos and be more integrated across other subject areas". Marshall (2014, pp. 106, 125) contends that "art integration's capacity to foster conceptual/procedural skills and metacognition is a powerful rationale for moving it into the core of education" and utilising this approach "could inspire new models of practice in an education system sorely in need of change".

In his discussion of the Australian Curriculum: The Arts, the lead writer for the Arts position paper, Professor John O'Toole (2019) highlighted the importance of tertiary training and professional development of both teachers and artists, arguing that this was where the greatest policy shift was required. In addition, he noted the external challenges of STEM (Science, Technology, Engineering and Mathematics), PISA (Programme for International Student Assessment) and the constant emphasis on literacy and numeracy related to external benchmarking and political pressure. In response, he advocated for greater collaboration between Arts educators and Arts industry practitioners by proposing that:

Teaching artists and artist-teachers are urgently needed to address the severe and endemic arts deficit in most pre-service generalist education, and the equal pedagogy deficit in most artist training. To comply with the Australian Curriculum, all pre-service teachers now need arts education, and most artists being trained in our conservatoria will spend at least some of their careers in educational contexts. However, many educational faculties and conservatoria traditionally and still ignore one another, and few as yet work closely together on this new imperative. With a will, this gap could easily be closed. (O'Toole, 2019, para. 13)

Bringing Arts educators and Arts industry practitioners together more proactively would provide mutual benefits for both. Stein (2004, p. 14) states that artists are "intrinsically motivated to change the entire school's climate into one in which arts integration is an integral part of the school curriculum". However, it is imperative that artists and teachers collaborate on this endeavour "with demonstrated mutual respect and understanding" (Snook \& Buck, 2014, p. 20). Felleman-Fattal (2017, p. 67) argues that arts integration is also a way of enacting a socially-just classroom where a range of diverse voices can freely express themselves "through language and non-verbal forms of communication, such as the visual arts, theatre, 
dance/movement and music" thereby envisioning and creating a more just society through "practical, creative and engaging teaching and learning". Integration of the visual and performing arts into other discipline areas creates new creative practices, expands theoretical frameworks and generates new tactical practices" (Chemi, 2014; Felleman-Fattal, 2017; Marshall, 2014).

During the pandemic, sectors such as science and health have worked together to provide a strong and consistent voice regarding measures to prevent and reduce transmission of the virus, including "tough but necessary social distancing and isolation requirements, putting public safety first, based on the advice of health authorities" (Payne, 2020, para. 10). Payne (2020, para. 28) reveals, however, that there has also been disinformation promoted about COVID-19 and that some countries are "using the pandemic to undermine liberal democracy to promote their own authoritarian models". The Arts and Humanities provide a vital counter-weight as they can inform and motivate a challenge to biased and limited views since "it is easier to treat people as objects to be manipulated if you have never learned any other way to see them" (Nussbaum, 2017, p. 23, cited in Eaude \& Catling, 2019). COVID-19 has provided an invaluable opportunity for the Arts education and Arts industry practitioners to unite, and utilise the extensive expertise and experience of practitioners in both areas to address current concerns regarding limited professional development, centralise the Arts in the curriculum through genuine arts integration approaches and to speak with one voice in ensuring the Arts are viewed as integral and critical to a holistic and democratic education.

\section{Methodology}

The participant researchers utilised a qualitative phenomenological approach in the 'Challenges, implications, and future of the Australian Curriculum: The Arts' project, which involved an "analytical and descriptive experience of phenomena by individuals in their everyday world" (Eddles-Hirsch, 2015, p. 251). This approach is grounded in the belief that that human experience is valid, thereby rejecting any characterising of the detached and scientific imperial tradition as a superior method of research (Eddles-Hirsch, 2015). As phenomenological research attempts to understand the essence of a phenomenon from individual experience (Eddles-Hirsch, 2015; Lester, 1999), the researcher becomes a visible presence in the research. Like the participants themselves, they act as an "interesting and subjective actor rather than a detached and impartial observer" (Lester, 1999, p. 1). This allows for considerable flexibility in approach, for as Holloway (1997) and Hycner (1999) contend, it is not possible to impose method on a phenomenon, "since that would do a great injustice to the integrity of that phenomenon" (p. 144). Far from being a limitation, the reticence to impose a method is a recognition that phenomena "have something to say to us - this is common knowledge among poets and painters" (Van Manen, 1997, cited in Groenewald, 2004, p. 44). This makes it an appropriate choice to explore the Australian Curriculum: The Arts through the perspective of five discipline experts from Dance, Drama, Media Arts, Music and Visual Arts. 
The data were collected from written phenomenological reflections about implementing The Australian Curriculum: The Arts during the period 2016-2021 provided by each of the participant researchers, who are also the authors of this paper. The intention of this research was to explore the phenomenon of the Australian Curriculum: The Arts through the experiences of arts educators and arts industry practitioners with a particular focus on the challenges, implications and future of their arts form. Coliazzi (cited in Groenewald, 2004, p. 50) describes this 'artistic process' as the drawing of meaning from written reflections: "the phenomenological researcher engage[s] in something which cannot be precisely delineated ... in that ineffable thing known as creative insight". The practitioner researchers had an initial meeting to discuss the scope of the project which included key issues they wished to explore. Each person wrote an individual reflection which provided an overview of what they perceived to be the uniqueness of their arts area including pedagogical processes, language and personal experiences. These were then incorporated into a longer narrative and shared with the group where emergent themes were identified: quality arts education; the arts and diversity; and the arts community. The participant researchers then wrote another reflection using the emergent themes and incorporating personal experiences related to these. These written reflections resulted in further refinement of the emergent themes into three key resonant themes: a quality arts education is an entitlement for every child and young person; the Arts provide important opportunities for children and young people from diverse backgrounds and cultures to demonstrate their learning, express themselves and participate; and arts educators need to work together to strengthen community understanding about the value of the Arts in education. The following section will present the themes as part of a collective phenomenological response informed by the collective voices of the five discipline experts who variously encompass roles as educators, arts educators, and/or arts industry practitioners: (Julie/Dance - arts educator/artist; Robyn/ Drama_-arts educator; Martin/Media Arts—other; Linda/Music_arts educator/artist; and Margaret/Visual Arts_-arts educator/artist) with italics used to denote direct quotations from their written reflections. The participant researchers are currently located in New South Wales, the Australian Capital Territory and Queensland.

\section{Resonant themes}

\section{A quality arts education is an entitlement for every child and young person}

The participant researchers reported that the five art form areas of Dance, Drama, Media Arts, Music and Visual Arts enrich our knowing, doing, being and becoming despite the growing global uncertainties exacerbated by COVID-19, crises caused by climate change, huge inequities between rich and poor, and ongoing international tensions. There was also acknowledgement that it is the right of every Australian child and young person to engage in a quality arts education. The researchers were unanimous in their evidence that each Australian student was entitled to learn about, in and through the five art forms across Foundation to Year 10. They discussed how they had each utilised research in their advocacy roles to emphasise the 
central role the Arts play in our lives, particularly, in nurturing and sustaining our social and emotional wellbeing (WHO, 2019). This included their experiences of using Arts-rich pedagogies and approaches and how they enable people to come to a sense of who they are, in addition to their role in fostering understanding of others' perspectives.

Julie reflected that Dance was previously part of the Physical Education curriculum and had traditionally been perceived, as an optional extra by those who had not had the opportunity to engage with this dynamic art form, apart from acknowledging its physical and social benefits. In relation to Drama, Robyn revealed that for decades it was located solely within the English curriculum. She noted that "while drama and dance became part of the Victorian, Queensland and Tasmanian curricula in the 1980s, a Creative Arts syllabus which included drama and dance was not published by the New South Wales Board of Studies until 2000" (Ewing, 2010, p. 21). In New South Wales this refers to Drama and Dance in the K-6 Creative Art Syllabus. The Drama and Dance Stage 6 Syllabuses were implemented in 1992. Each of the researchers referred to examples of the myriad ways the Arts have enabled children and young people they have worked with to imagine and aesthetically represent new possibilities and alternatives with the tools to communicate, question and challenge dominant hegemonies (Ewing, 2010, 2019a; Riley, 2021). Robyn described how through Drama students learn to walk in someone else's shoes and see the world from a different perspective which provides students with authentic opportunities to continue to develop curiosity, empathy and compassion, creative and critical thinking and a deep understanding of equity and social justice. The researchers have also experienced how the Arts action creative skills (Harris \& Carter, 2021), engage children and young people more deeply in learning in other curriculum areas (Gibson \& Ewing, 2020) and ensure that a learner's optimal achievement in non-Arts subjects can be realised (Fleming, et al., 2015a, 2015b).

Quality arts education emerged as a challenge and implication that arose in the reflections of quality arts education by the participant researchers. The researchers' concerns related particularly to the dearth of jurisdictional funding for teacher professional learning in the Arts, with huge disparities remaining in the provision of adequate arts learning time in pre-service teacher education programs as well as for early career and experienced teachers (Hipp \& Sulentic Dowell, 2019; RussellBowie, 2013). Julie discussed the importance of ongoing vigilance required for all the Arts forms, and particularly for dance due to the perception that it is only for 'talented' students with a particular body shape and physical abilities (RussellBowie, 2013; Snook \& Buck, 2014). She revealed this situation has been exacerbated by a lack of confidence amongst teachers in providing dance experiences and negative perceptions of dance which still persist (Hennessy, et al., 2001; Meiners, 2014; Snook \& Buck, 2014). Robyn described the range of factors, affirmed by the other participant researchers in relation to their arts form, that impact on a teacher's reticence to teach Drama including a lack of confidence and expertise in this art form, often stemming from their own school experiences. Linda referred to her experience of teachers lacking confidence in teaching music in the classroom and parents who were also reluctant to engage in music listening and music-making with their children (de Vries, 2009). She said that this jeopardised the 'entitlement' (ACARA, 
2011) to music and the musical growth of students. The researchers had all experienced the disparity that arose when more affluent families were able to "compensate for a paucity of arts in the school context by providing extra-curricular quality arts experiences" (Ewing, 2020, p. 76). The researchers recognised the historical undervaluing of the Arts in the curriculum, despite the rhetoric of the intended national Arts curriculum. Robyn noted the ongoing cuts to arts education in pre-service teacher education and the lack of provision for professional learning in the Arts in all education systems across the country. This has not helped early career teachers to gain an understanding of the potential role the Arts can, and should play, across the curriculum.

\section{The Arts provide important opportunities for children and young people from diverse backgrounds and cultures to demonstrate their learning, express themselves and participate}

The value of the Arts in providing opportunities for children and young people from diverse backgrounds to see themselves, their identities and their cultures reflected in the Arts curriculum was something each of the researchers had experienced. They were heartened by the current review of the Australian Curriculum that explicitly seeks to better embed the culture, knowledge, history and understandings of First Nations Australians, the world's oldest continuous living culture (Riley, 2021). In relation to Dance, Julie noted that many children and young people are denied equal access to Dance as an important non-verbal art form with expressive potential for those with disability, learning difficulties or language barriers (Risner \& Stinson, 2010). She revealed that it is currently a major challenge to support the study of dance in Aboriginal and Torres Strait Islander histories and cultures so that they become a priority in the Australian dance curriculum (Williams, 2014). Martin revealed that Media Arts enables students to engage online with cultures that may be very different to their own, with greater awareness of the challenges faced by others which can inform their understanding of social justice and how they can contribute to a more socially-just society (Dunscombe \& Stewart, 2009). Linda referred to the importance of recognising students' own experiences of music. She described her engagement with the music curriculum which scaffolds music teaching and learning for the early years of school, enabling teachers to start with music the students know and to incorporate repertoire already evident in the local community which validates the students' own music experience as they begin to learn in the more formal context of school.

Martin highlighted how when students become more aware of the reverberations of the past, they are able to consider their impact on the present, including in areas such as "social issues, equity, community and identity" (Hunger-Doniger, 2018, p. 51). In relation to Visual Arts, Margaret emphasised how artists hold a mirror up to society, providing us with a deeper and more considered perspective of societal issues and injustices. She drew parallels with the court jester, who could provoke the King "with absolute immunity and freedom to speak the truth" (Klein, 2007, p. 35). She has seen how visual arts enables students to experiment, take risks with 
media, and to be empowered by the act of creating something that helps them to make meaning of their world, which enhances their overall wellbeing. In line with the other researchers, Margaret emphasised the importance of students encountering the work of other artists to see how the Arts can be used in powerfully evocative ways to increase awareness of different voices and perspectives. She revealed that she often uses artworks to help provoke discussions about issues and to show the importance of learning from the past (Conaty, 2020). Quality arts education therefore assists students to make meaning from these encounters, develop empathy and integrate this knowledge into their lifeworlds (Stewart et al., 2005). Linda revealed how arts educators battle barriers of culture, class or education which permeate our schools and influence curriculum interpretation (Lorenza, 2018). When considered from this viewpoint, The Australian Curriculum: The Arts challenges us to reconsider and in fact, to re-define arts education in our schools so that we can move closer to enacting a 'socially-just' curriculum.

\section{Arts educators need to work together to strengthen community understanding about the value of the Arts in education}

Each of the researchers acknowledged that their arts discipline embodies distinctive ways of meaning making (Dyson, 2019). However, they also argued that the ability to synthesise and cross traditional discipline boundaries is integral to our future work together in, through and across the Arts. Each of the researchers has experienced genuine integration between the Arts forms, however, they acknowledged for this to work effectively, the Arts need to develop a shared narrative that recognises and respects the differences between the Arts disciplines but also enables genuine transdisciplinary configurations that deterritorialise subjects (Burnard, et al., 2021). Robyn described the impact of increasingly narrow and reductive forms of literacy and numeracy that linger in the enacted and experienced curriculum through siloed curriculum areas, increased high-stakes testing and the ongoing privileging of the competitive academic curriculum. Martin referred to the skills and expertise that participants in the arts-informed projects he has led have developed through Media Arts, which have enabled them to be active and considered contributors to local, national and global conversations in which their voices can be heard. Margaret shared her experience of designing a new arts education course for a teacher education program for generalist primary teachers based on the principles of genuine arts integration, both with the five arts forms and other discipline subjects, which was well accepted and moved seamlessly through the AITSL program accreditation process. She indicated this was because she had emphasised how critical it was for the pre-service teachers to develop the conceptual link between the two or more learning areas, to show how the Arts were leading the process and to ensure they were assessing both. During the development of the teacher education course she had been in contact with US colleagues who had also experienced issues in teaching genuine arts integration due to the fear that their discipline area would become marginalised in the process (Goldberg, 2021; O'Toole, 2019). The researchers all 
revealed that there have been missed opportunities in the Arts education sector to present good arguments which support genuine arts integration (Chemi, 2014).

The researchers discussed their experiences of partnering with arts organisations including their respective disciplinary professional associations and the national arts and arts industry associations. As the former and long-standing Chair of the National Advocates for Arts Education (NAAE), Julie revealed how invaluable this support has been in educating governments, policymakers, educational leaders and the community more broadly about the transformative nature of arts-rich pedagogies. She also articulated how young people's self-esteem and confidence grow through exposure to a broad arts education, but it requires ongoing and strong advocacy from artists, arts educators, arts bureaucrats and politicians. Margaret recalled meetings with various politicians who were very supportive of the Arts, however, were at times hampered by the ongoing tension between federal government funding and the state and territories responsibility for Education (Bezzina, et al., 2009; Brennan, 2011). Julie revealed that the option of an arts specialisation in pre-service primary education such as those offered by the University of South Australia would support primary teachers to feel confident and empowered to teach the Arts, and particularly dance. Martin described how he had seen arts industry practitioners bring something special to schools and inspire students through their lifelong commitment to the arts. Drawing upon her experiences as an artist and arts educator Margaret described how much credibility she had with her students by being a practicing artist (Carrillo \& Baguley, 2011; Kerby et al., 2016). She felt that the future of the arts relied on drawing upon and valuing the vast pedagogical expertise of teachers and the expertise of arts industry practitioners. Margaret felt this combination of experience and expertise could be a way to address the reduction in arts education courses, assist arts industry practitioners and enable students to genuinely experience the passion of people who have committed themselves to a career in the arts.

\section{Conclusion}

This paper challenges the extent to which the Arts are currently positioned in the Australian Curriculum, due to inconsistent implementation exacerbated by a lack of professional development for teachers. The participant researchers argue that the Arts should be centralised in the curriculum as a social justice issue. The five arts experts have provided important insights into the challenges, implications and potential future for the Arts in Australian education. The phenomenological research is unequivocal in the value of the Arts for learning with the current pandemic providing an opportune time to consider re-envisioning the Arts Curriculum. The Arts make children and young people's learning visible through both their process and outcomes. The significant contribution the Arts make in terms of student resilience, confidence and wellbeing, and in engaging children from diverse backgrounds through sensory and non-verbal approaches to enable them to express themselves is invaluable, particularly during times of crisis.

The Te Rito Toi project developed by Professor Peter O'Connor and arts educators from New Zealand and Australia during the pandemic has been the "first 
substantial curriculum resources in the arts and wellbeing for Primary schools in at least fifteen years" (O'Connor \& Estellés, 2021, p. 2). This reinforces the importance of Arts educators and the Arts industry practitioners working together to strengthen community understanding regarding the educational value of the Arts. O'Connor and Estellés (2021, p. 2) describe how the Te Rito Toi is a metaphor in Māori which represents how the arts (Toi) are at the centre of all growth. They also recognise the generosity of Michael Steedman Ngāti Whātua o Ōrākei, Ngāti Whātua, Te Uri o $\mathrm{Hau}$, Kaiarataki at the University of Auckland for sharing this knowledge:

The rito is kept safe by the leaves that surround it. Te Rito Toi recognises that the seed of the arts that start when we are young need to be protected and that the arts also help protect and help nourish the young. At a time of crisis, Te Rito Toi reminds us of the power of metaphor, of the grace and beauty to be found in understandings that derive from the natural and Māori worlds.

Arts educators are aware of the power of metaphor, of being able to convey complex ideas utilising the power of the Arts. However, in order to ensure stakeholders including students, teachers, the community and the government, are aware of the transformative potential of the Arts through all learning, it is important to speak with one strong and united voice, bringing together the collective experience and expertise of Arts educators and Arts industry practitioners.

\section{References}

ACARA. (2011). Shape of the Australian curriculum: the arts. Sydney: Australian Curriculum Assessment Reporting Authority Retrieved from http://acara.edu.au/verve/_resources/Shape_of_the_ Australian_Curriculum_The_Arts_-_Compressed.pdf.

ACARA. (2015). The Arts - Introduction. Retrieved from https://www.australiancurriculum.edu.au/f-10curriculum/the-arts/.

ACARA. (2021). The three dimensions of the Australian Curriculum. [Video]. YouTube. https://www. youtube.com/watch?v=p0VP33V3Dyw.

Australia Council for the Arts. (2020). Creating our Future: Results of the national arts participation survey. Retrieved on April 13, 2021 from https://www.australiacouncil.gov.au/research/creat ing-our-future.

Australian Government (Dec, 2019). Alice Springs (Mparntwe) Education Declaration. Education Council. Retrieved from https://docs.education.gov.au/documents/alice-springs-mparntwe-educationdeclaration.

Australian Government. (2021). Job-ready graduates package. Retrieved on May 1, 2021 from https:// www.dese.gov.au/job-ready.

Baguley, M., Kerby, M., MacDonald, A., \& Cruickshank, V. (2020). Strangers on a train: The politics of collaboration. Australian Educational Researcher, 48, 183-208. https://doi.org/10.1007/ s13384-020-00386-9

Barrett, M. S. (2019). Playing in and through the musical worlds of children. In S. Alcock \& N. Stobbs (Eds.), Re-thinking play as pedagogy (pp. 99-118). Routledge.

Barton, G., \& Baguley, M. (2017). The Palgrave Handbook of Global Arts Education. Palgrave Macmillan.

Battersby, S., \& Cave, A. (2014). Preservice classroom teachers' perceived attitudes, confidence, beliefs, and self-efficacy toward integrating music in the elementary curriculum. Applications of Research in Music Education, 32(2), 52-59.

Berry, B. (2020). Teaching, learning and caring in the post-COVID era. Phi Delta Kappan, 102(1), $14-17$. 
Bezzina, M., Starratt, R. J., \& Burford, C. (2009). Pragmatics, politics and moral purpose: The quest for an authentic national curriculum. Journal of Educational Administration, 47(5), 545-556.

Brennan, M. (2011). National Curriculum: A Political-educational Tangle. Australian Journal of Education, 55(3), 259-280. https://doi.org/10.1177/000494411105500307

Bresler, L. (Ed.). (2007). International handbook of research in arts education. Dordrecht: Springer.

Burnaford, G., Aprill, A., \& Weiss, C. (Eds.). (2011). Renaissance in the classroom: Arts integration and meaningful learning. Chicago Arts Partnerships in Education.

Burnard, P., Colucci-Gray, L., \& Sinha, P. (2021). Transdisciplinarity: Letting arts and science teach together. Curriculum Perspectives, 41(1), 113-118. https://doi.org/10.1007/s41297-020-00128-y

Burridge, S., \& Dyson, J. (Eds.). (2020). Shaping the landscape: Celebrating dance in Australia. NY: Routledge.

Carrillo, C., \& Baguley, M. (2011). From school teacher to university lecturer: Illuminating the journey from the classroom to the university for two arts educators. Teaching and Teacher Education, $27(1), 62-72$.

Chemi, T. (2014). The artful teacher: A conceptual model for arts integration in schools. Studies in Art Education, 56(1), 370-383.

Choi, M., Tessler, H., \& Kao, G. (2020). Arts and crafts as an educational strategy and coping mechanism for Republic of Korea and United States parents during the COVID-19 pandemic. International Review of Education, 66, 715-735. https://doi.org/10.1007/s11159-020-09865-8

Commonwealth of Australia (2021). Budget 2021-22 - Securing Australia's Recovery: Supporting Australians through COVID-19. Retrieved on 1 May, 2021 from https://budget.gov.au/2021-22/conte nt/download/glossy_covid19.pdf.

Comte, M. (1988). The arts in Australian schools: The past fifty years. Australian Journal of Music Education, 1(1), 102-121.

Conaty, S. M. (2020). The value of art history in a pandemic: Teaching as a healing force. Historical Perspectives in Art. Fall, 1-7. Retrieved on May 15, 2021 from https://www.jhrehab.org/wp-content/ uploads/2020/11/Conaty_Art_History_in_a_Pandemic_Fall_2020-1.pdf.

Cosaitis, W. (2011). The introduction of the Shape of the Australian Curriculum: The Arts. Victorian Journal of Music Education, 1, 20-29.

Davis, J. H. (2008). Why our schools need the arts. Teachers College Press.

Dezuanni, M. (2017). Media Arts. In C. Sinclair, N. Jeanneret, J. O’Toole, \& M. A. Hunter (Eds.), Education in the Arts (3rd ed., pp. 128-142). Oxford University Press.

Duffy, C., \& Sadler, R. (2020). NAPLAN was cancelled due to COVID-19 and some parents don't want it back. ABC News. Retrieved on Feb 14, 2021 from https://www.abc.net.au/news/2020-09-10/ naplan-cancelled-due-to-covid-19-some-parents-want-it-gone/12641570.

Dunscombe, R., \& Stewart, C. (2009). A view of literacy through media arts. In J. Dyson (Ed.), More than Words can Say (pp. 94-103). National Advocates for Arts Education. Retrieved from https:// naae.org.au/publications.

Dye, J. (2020, March 18). Arts industry seeks $\$ 850$ million rescue package. The Sydney Morning Herald. Retrieved May 25, 2021 from https://www.smh.com.au/culture/theatre/arts-industry-seeks-850million-rescue-package-20200317-p54aud.html.

Dyson, J. (2019). (Ed.). More than words can say - a view of literacy through the arts. National Advocates for Arts Education. Retrieved on 14 May, 2021 from https://naae.org.au/news/a-new-editionof-more-than-words-can-say-a-view-of-literary-through-the-arts.

Eaude, T., \& Catling, S. (2019). May). The role of the humanities in a balanced and broadly based primary curriculum. Impact: Journal of the Chartered College of Teaching., 62, 53-64.

Eddles-Hirsch, K. (2015). Phenomenology and educational research. International Journal of Advanced Research, 3(8), 251-260.

Eisner, E. (2002). The arts and the creation of mind. Yale University Press.

Eisner, E. (2009). The Lowenfeld Lecture 2008: What education can learn from the arts. Arts Education, 62(2), 6-9. https://doi.org/10.1080/00043125.2009.11519006

Eisner, E. W., \& Vallance, E. (1974). Five conceptions of curriculum: Their roots and implications for curriculum planning. In E. W. E. E. Vallance (Ed.), Conflicting Conceptions of Curriculum (pp. 1-18). McCutchan Publishing.

Eltham, B. (2014, Oct 24). National arts curriculum: Media arts takes the fall. Arts Hub. Retrieved on June 15, 2021 from https://www.artshub.com.au/2014/10/24/national-arts-curri culum-media-arts-takes-the-fall-246274/.

Ewing, R. (2019a). Arts-rich pedagogies and becoming deeply literate. Australia: Drama. 
Ewing, R. (2020). The Australian Curriculum: The arts. A critical opportunity. Curriculum Perspectives, $40,75-81$.

Ewing, R. (2010). The arts and Australian education: Realising potential. Australian Council for Educational Research.

Ewing, R. (2019b). Foreword. In J. Dyson (Ed.). More than words can say. A view of literacy through the arts. The National Advocates for Arts Education. Retrieved on 15 June, 2021 from https://naae.org. au.

Felleman-Fattal, L. R. (2017). Action research in preservice teachers' arts-integration pedagogies for social justice teaching and learning. Childhood Education, 93(1), 66-72. https://doi.org/10.1080/ 00094056.2017 .1275244

Fleming, M., Bresler, L., \& O'Toole, J. (2015a). The Routledge international handbook of the arts and education. Routledge.

Fleming, J., Gibson, R., \& Anderson, M. (Eds.). (2015b). How arts education makes a difference. NY: Routledge.

Freire, P. (1998). Pedagogy of freedom. Ethics, democracy and civic courage. NY: Rowman and Littlefield Publishers.

Gardner, H. (1983). Frames of mind: The theory of multiple intelligences. Basic Books.

Gibbs, L., Mutch, C., O'Connor, P., \& MacDougall, C. (2013). Research with, by, for and about Children: Lessons from disaster contexts. Global Studies of Childhood, 3(2), 129-141.

Gibson, R., \& Ewing, R. (2020). Transforming the curriculum in the Arts (2nd ed.). UK: Palgrave Macmillan.

Gilbert, R. (2019). General capabilities in the Australian curriculum: Promise, problems and prospects. Curriculum Perspectives, 39, 169-177. https://doi.org/10.1007/s41297-019-00079-z

Gleeson, J., Klenowski, V., \& Looney, A. (2020). Curriculum change in Australia and Ireland: A comparative study of recent reforms. Journal of Curriculum Studies, 52(4), 478-497.

Goldberg, M. (2021). Arts integration: teaching subject matter through the arts in multicultural settings (6th ed.). NY: Routledge.

Grierson, E. (2011). Art and creativity in the global economies of education. Educational Philosophy and Theory, 43(4), 336-350. https://doi.org/10.1111/j.1469-5812.2009.00550.x

Griss, S. (1994). Creative movement: A language for learning. Educational Leadership, 51(5), 78-80.

Groenewald, T. (2004). A phenomenological research design illustrated. International Journal of Qualitative Methods, 3(1), 42-55.

Guibert, G., \& Hyde, I. (2021, Jan 4). COVID-19 Weekly outlook. COVID19- RSFLG Data and assessment working group. Argonne National Laboratory. Retrieved on May, 12021 from https://www. arts.gov/sites/default/files/COVID-Outlook-Week-of-1.4.2021-revised.pdf.

Haase, A. (2020). Covid-19 as a social crisis and justice challenge for cities. Frontiers in Sociology, 5, 1-7. https://doi.org/10.3389/fsoc.2020.583638

Hands, K. (2020, May 25). The problem with arts funding in Australia goes right back to its inception. The Conversation. Retrieved on June 15, 2021 from https://theconversation.com/the-problem-witharts-funding-in-australia-goes-right-back-to-its-inception-138834.

Harris, A., \& Carter, M. (2021). Applied Creativity and the Arts. The Arts, Point and Counterpoint, Curriculum Perspectives, 41(1), 107-112. https://doi.org/10.1007/s41297-020-00127-z

Harris, G. (2021, July 22). UK government approves 50\% funding cuts for arts and design courses. The Art Newspaper. Retrieved on July 23, 2021 from https://www.theartnewspaper.com/news/uk-gover nment-sanctions-50-funding-cut-for-arts-and-design-courses.

Hennessy, S., Rolfe, L., \& Chedzoy, S. (2001). The factors which influence student teachers' confidence to teach the arts in the primary classroom. Research in Dance Education, 2(1), 53-71. https://doi. org/10.1080/14647890123720

Hipp, J., \& Sulentic Dowell, M.-M. (2019). Challenges and supports to elementary teacher education: Case study of preservice teachers' perspectives on arts integration. Journal for Learning through the Arts. https://doi.org/10.21977/D915144538

Holloway, I. (1997). Basic concepts for qualitative research. Blackwell Science.

Hycner, R. H. (1999). Some guidelines for the phenomenological analysis of interview data. In A. Bryman \& R. G. Burgess (Eds.), Qualitative research (Vol. 3, pp. 143-164). Sage, Newbury Park.

Joseph, A. (2020). What is the future of arts education in the midst of a pandemic? It's essential, virtual, and hybrid for now! International Dialogues on Education, 7, 61-80.

Kerby, M., Baguley, M., \& Tuppurainen-Mason, E. (2016). Interpreting the Anzac legacy: Reflective accounts of artistic practice. Art Education Australia, 37(2), 116-132. 
Klein, S. (2007). Art and Laughter. NY, New York: I.B. Tauris \& Company.

Lester, S. (1999). An introduction to phenomenological research. Stan Lester Developments.

Lingard, B., Thompson, G., \& Sellar, S. (2016). National testing from an Australian perspective. In B. Lingard, G. Thompson, \& S. Sellar (Eds.), National testing in schools: An Australian perspective (pp. 1-17). NY: Routledge.

Lorenza, L. M. (2018). Curriculum change and teachers' responses: a NSW case study. [Unpublished doctoral dissertation, The University of Sydney]. http://hdl.handle.net/2123/18901.

Lorenza, L. (2020, Oct 23). Learning acting online in a pandemic. NTRO - Non Traditional Research Outcomes. Retrieved on 15 May, 2021 from from https://nitro.edu.au/articles/2020/10/23/learningacting-online-in-a-pandemic.

Mak, H. W., Fluharty, M., \& Fancourt, D. (2021). Predictors and impacts of arts engagement during the COVID-19 pandemic: Analyses of data from 19, 384 adults in the COVID-19 social study. Frontiers in Psychology. https://doi.org/10.3389/fpsyg.2021.626263

Marshall, J. (2014). Transdisciplinarity and art integration: Toward a new understanding of arts-based learning across the curriculum. Studies in Art Education: A Journal of Issues and Research, 55(2), $104-127$.

Marshman, I., \& Larkins, F. (2020, June 24). The government is making 'job-ready' degrees cheaper for students - but cutting funding to the same courses. The Conversation. Retrieved on April 17, 2021 from https://theconversation.com/the-government-is-making-job-ready-degrees-cheaper-for-stude nts-but-cutting-funding-to-the-same-courses- 141280.

Meiners, J. (2014). So we can dance! Towards a new inclusive Australian dance curriculum - power, contestations and settlements. International Journal of Education through Art, 10(2), 221-234. https:// doi.org/10.1386/eta.10.2.221_1

Ministerial Council on Education Employment Training and Youth Affairs (MCEETYA). (2008). Melbourne declaration on educational goals for young Australians. Melbourne, Vic: MCEETYA, Retrieved from http://www.curriculum.edu.au/verve/_resources/National_Declaration_on_the_ Educational_Goals_for_Young_Australians.pdf.

Morgan, I. (2018). Arts education and citizenship: A pedagogical framework. Journal of Dance Education, 18, 95-102. https://doi.org/10.1080/15290824.2018.1481964

Morris, L. (2020, Aug 25). Social cohesion, happiness: parents see value in introducing young kids to the arts. The Sydney Morning Herald. Retrieved on May 15, 2021 from https://www.smh.com.au/ culture/theatre/social-cohesion-happiness-parents-see-value-in-introducing-young-kids-to-the-arts20200824-p55owh.html.

Moss, J., Godinho, S. C., \& Chao, E. (2019). Enacting the Australian Curriculum: Primary and secondary teachers' approaches to integrating the curriculum. Australian Journal of Teacher Education, $44(3), 24-41$.

National Advocates for Arts Education (NAAE). (2020). Changes to creative arts university fees. Retrieved on May 25, 2021 from https://naae.org.au/news/changes-to-creative-arts-university-fees.

National Art Education Association (NAEA) (2021). Arts education is essential: A unified statement from arts and education organizations. Retrieved on May 20, 2020 from https://www.arteducators.org/ news/articles/688-arts-education-is-essential-a-unified-statement-from-arts-and-education-organ izations.

Noddings, N. (Ed.). (2005). Educating citizens for global awareness. Amsterdam: Teachers College Press.

Nussbaum, M. C. (2017). Not for profit: Why democracy needs the humanities. NJ: Princeton University Press.

OECD. (2020, Nov 10). The territorial impact of COVID-19: Managing the crisis across levels of government. Retrieved from https://www.oecd.org/coronavirus/policy-responses/the-territorialimpact-of-covid-19-managing-the-crisis-across-levels-of-government-d3e314e1/.

O'Connor, P., \& Estellés, M. (2021). Shot of love: The art of care in schools post disaster. Pastoral Care in Education. https://doi.org/10.1080/02643944.2021.1951341

O'Toole, J. (2018). The Australian Curriculum for the Arts - five years old: Its conception, birth and first school report. Australian Art Education, 39(3), 427-440.

O'Toole, J., Stinson, M., \& Moore, T. (2009). Drama and curriculum: A giant at the door. NY: Springer.

O'Toole, J. (2013). A commonwealth of arts? Writing a national curriculum for arts in Australia. In E. Liebau, E. Wagner \& M. Wyman (Eds.), International Yearbook for Research in Arts Education (Vol. 1, pp. 203-209). Waxmann. 
O'Toole, J. (2019). Mind the gap - some implications of the Australian Curriculum: Arts for policy change in tertiary arts and education training. Non Traditional Research Outcomes. Retrieved on Dec 15, 2020 from https:/nitro.edu.au/articles/2019/3/1/mind-the-gap-some-implications-of-theaustralian-curriculum-arts-for-policy-change-in-tertiary-arts-and-education-training.

Pascoe, R., S. Leong, J. MacCallum, E. Mackinlay, K. Marsh, B. Smith, T. Church, and A. Winterton. (2005). National Review of School Music Education: Augmenting the Diminished. Canberra, ACT. Department of Education, Science and Training.

Payne, M. (2020, June 16). Australia and the world in the time of COVID-19. National Security College, Australian National University. [Speech by Senator the Hon. Marise Payne - Minister for Foreign Affairs; Minister for Women]. Retrieved on Dec 15, 2020 from https://www.foreignminister.gov.au/ minister/marise-payne/speech/australia-and-world-time-covid-19.

Rago, J., \& Gibson, R. (2021). How visual arts can promote perseverance, confidence and creative risktaking in young students. Australian Art Education, 42(1), 50-69.

Rea, N. (2021, July 22). The U.K. Government will slash arts funding in higher education by 50 percent and redirect funds to science and medicine. Artnet. Retrieved on July 25, 2021 from https://news. artnet.com/art-world/england-univeristy-arts-cuts-1991525.

Riley, L. (2021). The use of Aboriginal cultural traditions in art. Curriculum Perspectives, 41(1), 85-92. https://doi.org/10.1007/s41297-020-00124-2

Risner, D., \& Stinson, S. W. (2010). Moving social justice: Challenges, fears and possibilities in dance education. International Journal of Education \& the Arts, 11(6). Retrieved from http://www.ijea. org/v11n6/.

Russell-Bowie, D. E. (2013). What? Me? Teach dance? Background and confidence of primary preservice teachers in dance education across five countries. Research in Dance Education, 14(3), 216232. https://doi.org/10.1080/14647893.2012.722614

Sabol, F. R. (2021). Art education during the COVID-19 pandemic: The journey across a changing landscape. Art Education Policy Review. https://doi.org/10.1080/10632913.2021.1931599

Sears, A., \& Clark, P. (2020, Sept 29). Stop telling students to study STEM instead of humanities for the post-coronavirus world. The Conversation. Retrieved on May 4, 2021 from https://theco nversation.com/stop-telling-students-to-study-stem-instead-of-humanities-for-the-post-coron avirus-world-145813.

Sikkema, S., Lee, J., Spilberg, J., Dahn, M., Yankova, N., \& Peppler, K. (2021). How the arts can UNLOCK a closed curriculum. Phi Delta Kapan. https://doi.org/10.1177/00317217211013932

Snook, B., \& Buck, R. (2014). Artists in schools: "Kick Starting" or "Kicking Out" Dance from New Zealand classrooms. Journal of Dance Education, 14(1), 18-26. https://doi.org/10.1080/15290824. 2013.835052

Snyder, L., Klos, P., \& Grey-Hawkins, L. (2014). Transforming teaching through arts integration. Journal for Learning through the Arts. https://doi.org/10.21977/D910119308

Stein, D. (2004). Wearing two hats: The case of visiting artists in the classroom. In J. Solomon (Ed.), Good work project, Number 29 (pp. 1-23). NY: Cambridge.

Stewart, M., \& Walker, S. R. (Eds.). (2005). Rethinking curriculum in art. Davis.

Tam, P.-C. (2020). Response to COVID-19 'Now I send you the rays of the sun': A drama project to rebuild post-COVID-19 resilience for teachers and children in Hong Kong. Research in Drama Education: THe Journal of Applied Theatre and Performance, 25(4), 631-637. https://doi.org/10. 1080/13569783.2020.1816816

Turner, B. (2020, Oct 2). It's not about 'we're special': why it's crunch time for the arts sector. The Sydney Morning Herald. Retrieved on May 1, 2021 from https://www.smh.com.au/culture/music/it-snot-about-we-re-special-why-it-s-crunch-time-for-the-arts-sector-20200907-p55t6c.html.

Tuttle, L., \& Hansen, D. (2021). Arts education in a virtual learning environment: an introduction to the lessons, policies, budgets and practices from the COVID-19 era. Arts Education Policy Review. https://doi.org/10.1080/10632913.2021.1931600

UNESCO. (2020, May 24). Message from Audreny Azoulay, Director-General of UNESCO, on the occasion of International Arts Education Week, 25-31 May. Retrieved on May 20, 2021 from https://en. unesco.org/commemorations/artseducationweek.

UNESCO. (2021a, June). Cultural and creative industries in the face of COVID-19: An economic outlook. Retrieved on July 1, 2021 from https://en.unesco.org/creativity/publications/cultural-creativeindustries-face-covid-19.

UNESCO. (2021b, May 26). Join UNESCO to celebrate the 2021 International Arts Education Week! [Video]. YouTube. https://www.youtube.com/watch?v=eCtRKHRIA7U. 
University of Auckland. (n.d.). Te Rito Toi. Centre for Arts and Social Transformation. Retrieved on Mar 1, 2021 from https://www.teritotoi.org/

Vasileva, M., Alisic, E., \& De Young, A. (2021). COVID-19 unmasked: preschool children's negative thoughts and worries during the COVID-19 pandemic in Australia. European Journal of Psychotramatology, 12(1), 1-12. https://doi.org/10.1080/20008198.2021.1924442

de Vries, P. (2009). Music at home with the under fives: What is happening? Early Childhood Development and Care, 179(4), 395-405. https://doi.org/10.1080/03004430802691914

Williams, J. (2014). Introducing Torres Strait Island dance to the Australian high school physical education curriculum. Asia Pacific Journal of Education, 34(3), 305-318. https://doi.org/10.1080/02188 791.2013 .823380

World Health Organisation (WHO). (2019). What is the evidence on the arts improving health? A scoping review. Retrieved on June 15, 2021 from http://www.euro.who.int/en/publications/abstracts/what-isthe-evidence-on-the-role- of-the-arts-in-improving-health-and-well-being-a-scoping-review-2019

Publisher's Note Springer Nature remains neutral with regard to jurisdictional claims in published maps and institutional affiliations.

Martin Kerby is an Associate Professor in the School of Education at the University of Southern Queensland. His specialisation is in History with a particular focus on artistic and cultural representations of conflict. Associate Professor Kerby has expertise in biographical research, case study, narrative inquiry, and arts-informed research. He has sole authored six books and has been awarded two competitive Queensland Anzac Centenary grants (2014; 2017), a national Australian Government Anzac Centenary Arts and Culture Fund Public Grant (2015), and a State Library of Queensland Fellowship (2018). Associate Professor Kerby co-edited The Palgrave Handbook of Artistic and Cultural Responses to War: Australasia, the British Isles, and the United States. He is the current Editor of the Australian Art Education journal.

Linda Lorenza is Head of course and Senior Lecturer in Theatre at Central Queensland University. Her teaching areas include acting, drama, theatre studies and arts education. Dr Lorenza's PhD thesis, Curriculum change and teachers' responses: a NSW case study (2018) has more than 3000 downloads. Her research interests include music, drama, and applied arts. Upon graduating with a Bachelor of Arts majoring in Linguistics her first full time employment was in STEM research. Dr Lorenza was the Senior Project Officer for the Arts at the Australian Curriculum, Assessment and Reporting Authority (ACARA) for the development of the Australian curriculum: the Arts.

Julie Dyson AM is an arts advocate working across several organisations, including as a board member of Ausdance National. She is the immediate past chair of the National Advocates for Arts Education (NAAE), and is the former national director of Ausdance, where her work included policy development, advice to funding bodies, government departments, companies and individual artists. She works as a volunteer on the dance collections at the National Library of Australia, and has edited many publications, including Shaping the Landscape - Celebrating Dance in Australia and Shifting Sands: Dance in Asia and the Pacific.

Robyn Ewing $A M$ is Professor Emerita, Teacher Education and the Arts, The University of Sydney. and Co-Director of the Creativity in Research, Engaging the Arts, Transforming Education (CREATE) Centre. Her current research interests include: the use of drama-rich pedagogy with literature to develop students' imaginations and critical literacies; teacher education, especially the experiences of early-career teachers, mentoring and the role of reflection in professional practice; picture books and early literacy development; and sustaining curriculum innovation She has worked in partnership with Sydney Theatre Company on the teacher professional learning program 'School Drama' since 2009.

Margaret Baguley is a Professor in Arts Education, Curriculum and Pedagogy at the University of Southern Queensland. Her research areas of interest include visual arts education, creative leadership, creative collaboration and group dynamics. She is currently the President of Art Education Australia (AEA) and the visual arts representative on the National Advocates for Arts Education (NAAE). 